\title{
The study of expanded tri-lobed flap in a rabbit model: possible flap model in ear reconstruction?
}

\author{
Eray Copcu*1, Mesut Yazici², Barlas Etensel2, Yakup Yüreklý 3 and \\ Muharrem Balkaya ${ }^{4}$
}

Address: ${ }^{1}$ Department of Plastic and Reconstructive Surgery, Medical Faculty, Adnan Menderes University, Aydin, TURKEY, ${ }^{2}$ Department of Pediatric Surgery, Medical Faculty, Adnan Menderes University, Aydin, TURKEY, ${ }^{3}$ Department of Nuclear Medicine, Medical Faculty, Adnan Menderes University, Aydin, TURKEY and ${ }^{4}$ Department of Physiology, Veterinary Faculty, Adnan Menderes University, Aydin, TURKEY

Email: Eray Copcu* - copcu@lycos.com; Mesut Yazici - myazici@adu.edu.tr; Barlas Etensel - betensel@adu.edu.tr;

Yakup Yüreklý - yyurekli@adu.edu.tr; Muharrem Balkaya - mbalkaya@adu.edu.tr

* Corresponding author

Published: 16 December 2003

BMC Surgery 2003, 3:13
Received: 23 July 2003

Accepted: 16 December 2003

This article is available from: http://www.biomedcentral.com/I47I-2482/3/13

(C) 2003 Copcu et al; licensee BioMed Central Ltd. This is an Open Access article: verbatim copying and redistribution of this article are permitted in all media for any purpose, provided this notice is preserved along with the article's original URL.

\begin{abstract}
Background: Local flaps are widely used in reconstructive surgery. Tri-lobed skin flap is a relatively new flap and there has been no experimental model of this flap. This flap can be used for repair of full thickness defects in the face, ears and alar region. Based on the size of ears in a rabbit, we designed a model of ear reconstruction using expanded tri-lobed flap. Local flaps are more advantageous in that they provide excellent color and texture matching up with those of the face, adequately restore ear contour, place scars in a favorable location and ideally accomplish these goals in a single stage with minimal donor site morbidity.
\end{abstract}

Methods: Eight adult New Zealand rabbits were divided into two groups. $50 \mathrm{ml}$ round tissue expander were implanted to four rabbits. After completion of the expansion, a superiorly based tri-lobed flap was elevated and a new ear was created from the superior dorsal skin of each rabbit. Scintigraphy with Technetium-99m pertecnetate was performed to evaluate flap viability.

Results: Subtotal flap necrosis was seen in all animals in non-expanded group. New ear in dimensions of the original ear was created in expanded group without complication. Perfusion and viability of the flaps were proved by Technetium- $99 \mathrm{~m}$ pertecnetate scintigraphy.

Conclusion: According to our knowledge this study is the first to demonstrate animal model in tri-lobed flap. Also, our technique is the first application of the trilobed flap to the possible ear reconstruction. We speculated that this flap may be used mastoid based without hair, in human. Also, tri-lobed flap may be an alternative in reconstruction of cylindrical organs such as penis or finger.

\section{Background}

Although local flaps are widely used, tri-lobed skin flap is not popular. Tri-lobed flaps as a modification of bi-lobed flaps were first reported by Harashina in 1977, and Weerda presented his experiences with this flap in facial defects in $1978[1,2]$. As far as we know, there have been less than 10 reports on the flap. Ohtsuka used this flap in facial reconstruction in a patient with hemangioma [3]. Since tri-lobed flap has a right angle, Tanabe and Pompei used this flap for reconstruction of inverted nipple $[4,5]$. 
Masakazu used perforator-based tri-lobed flap for coverage of lumbosacral defects [6]. Copcu proposed this flap for reconstruction of the posterior sulcus of the ear because the angled, erect shape of the posterior ear can be obtained with this flap [7].

Ear reconstruction (total or subtotal) is one of most difficult tasks in Plastic Surgery. The requisites for a successful total ear reconstruction are twofold. One is the construction of a genuine cartilage framework and the other is the provision of durable yet thin coverage [8]. An ideal flap for ear reconstruction should provide color and texture matching with the recipient area, be thin for excellent coverage, safe and resistant to traumas. Moreover, it should create a sufficient angle as in the original shape of the ear. Although more than twenty flaps have been described for ear reconstruction, there is no animal model for flaps in ear reconstruction. Tissue expanders are the indispensable materials for plastic surgeons to get a new and durable tissue. Tissue expansion has given surgeons the ability to harvest large flaps of color-, thickness-, and texturematched skin while simultaneously minimizing donorsite defects [9]. The superior match of color and texture achieved with tissue expanders as compared with the results achieved with conventional methods of microtia repair is one of the most important merits of the expansion procedure [10]. The aim of this study was to reveal that expanded tri-lobed flap elevated from the peri-auricular area could be a model for creating of a new ear in rabbits.

\section{Methods}

This study was carried out in Laboratory of Experimental Studies, Adnan Menderes University. We used eight adult New Zealand white rabbits weighing between 2-3 kg. Each rabbit was put in a separate cage. After they adapted to the environment, the experiments were done. The whole back was shaved in all rabbits. The animals were anesthetized with a combination of intramuscularly injected ketamin hydrochloride $(35 \mathrm{mg} / \mathrm{kg}$ ) and xylazine $(5 \mathrm{mg} / \mathrm{kg}$ ). Rabbits were randomly divided into two groups. The operations were performed under aseptic conditions.

\section{Flap design}

Tri-lobed flap was designed for ear reconstruction. Sizes of flaps were the same as in the original rabbit ear. Lengths of the arms of the flap were also the same as in the original ear of each rabbit. First, sizes of the ears of each rabbit were calculated. Bases of the flaps were located between the two ears of the rabbits. All lobes of the flaps were elliptical, and there was a $45^{\circ}$ angle between them (Figure 1). The three arms of the skin flaps were elevated from the deep fascia. The last two arms (arms B and C) were elevated from the tip to the end of the base and these two

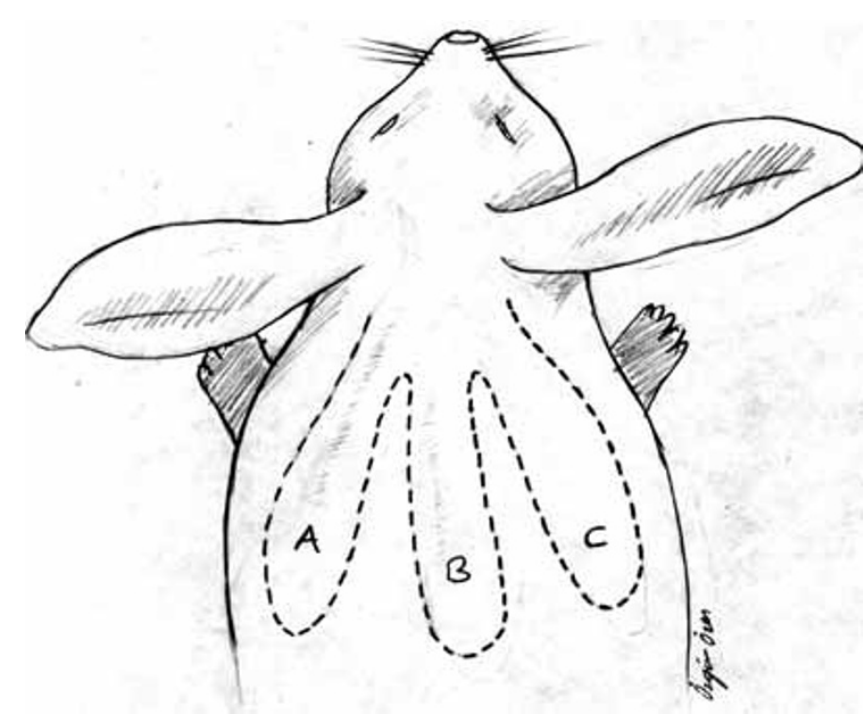

Figure I

Preparation of the tri lobed flap: Landmarks of the flap.

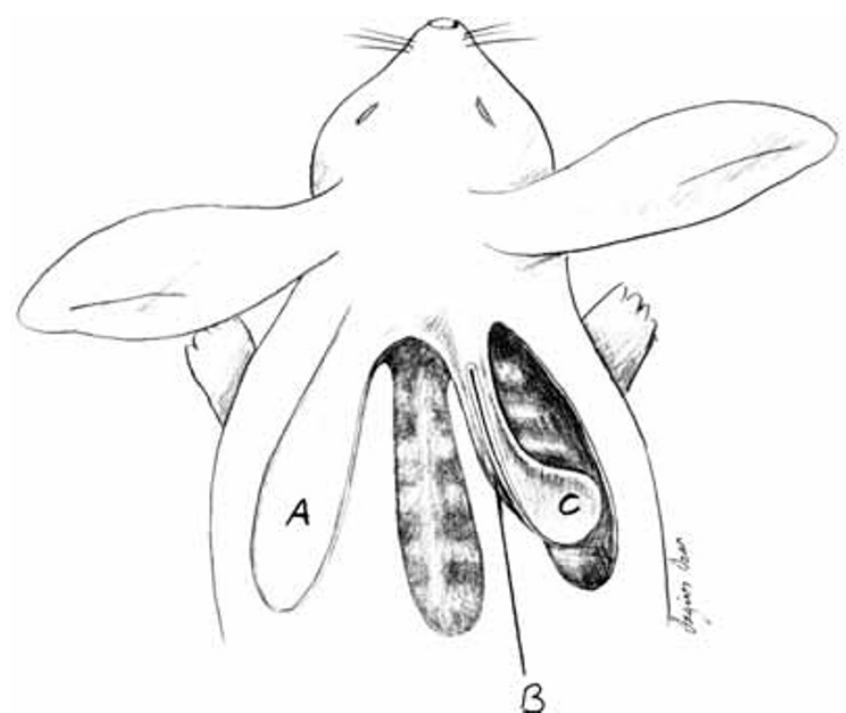

Figure 2

Elevation of the flap.

arms were sutured with $4 / 0$ prolene to create a new ear (Figure 2 and 3 ). The defect caused by the elevations of the arms $\mathrm{B}$ and $\mathrm{C}$ were closed by transposition of the arm A (Figure 4). 


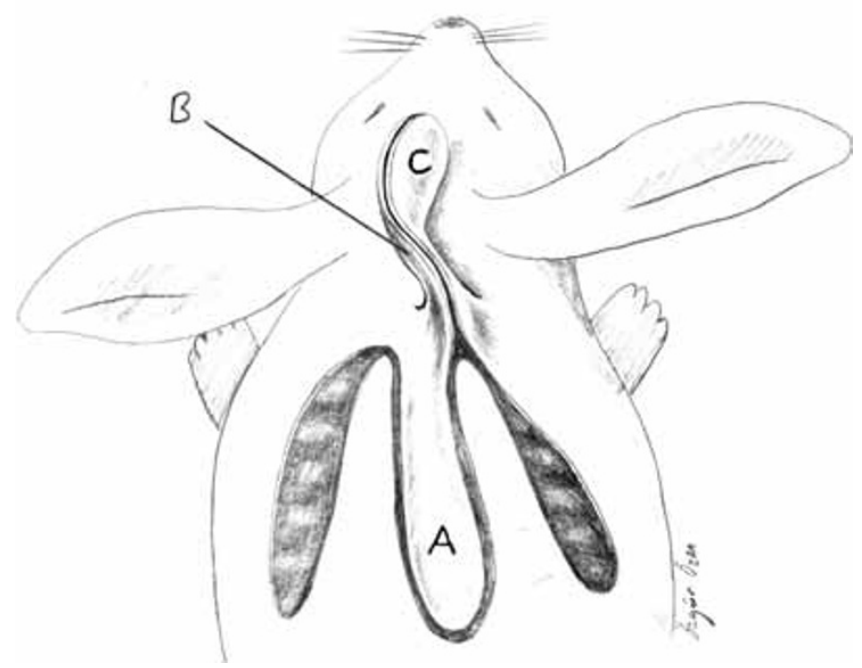

Figure 3

Creating of new ear.

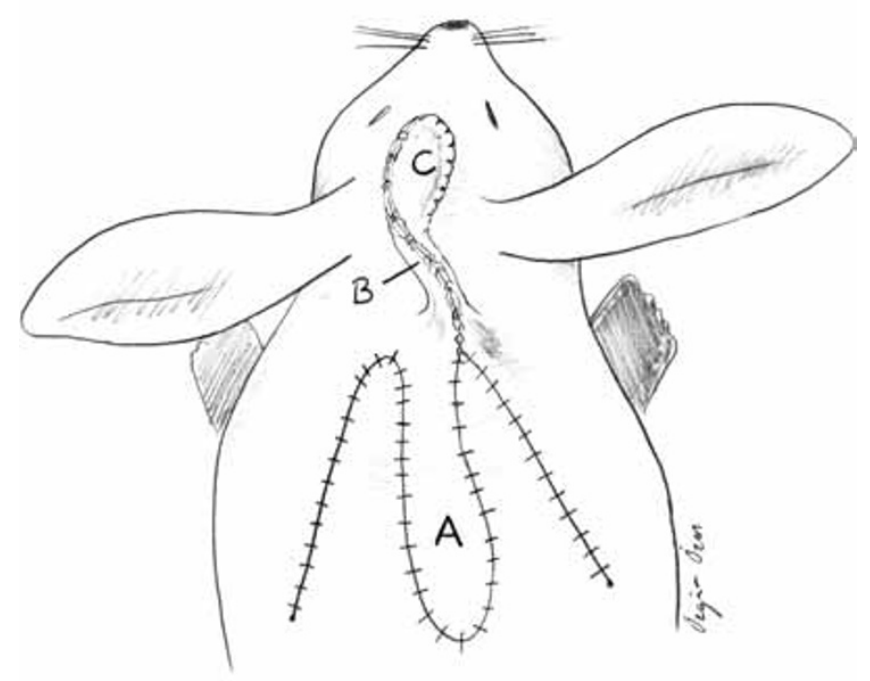

Figure 4

Closing of the donor area.

\section{Application of tissue expanders}

Tissue expanders, which were $50 \mathrm{ml}$ and round (Nagor Ltd, England), were implanted to the upper dorsal area of the four rabbits in Group 1 before the elevation of the flap. (Figures 5, 6, 7) For implantation of tissue expanders, $2 \mathrm{~cm}$ long incisions were made perpendicular to the areas where the expanders were to be placed and pockets of the sufficient size to allow insertion of a $50 \mathrm{ml}$ round

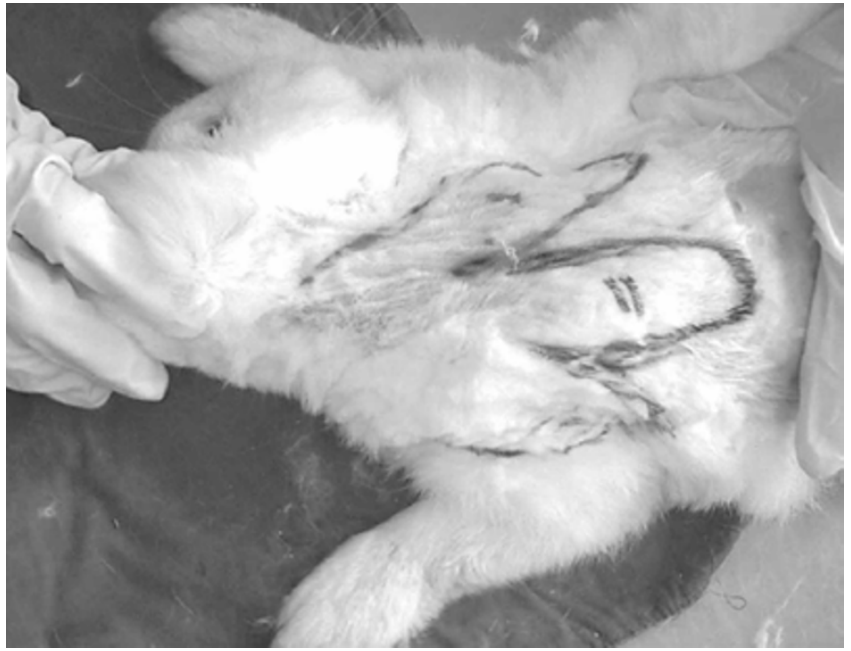

Figure 5

Design of the flap in superior dorsal skin of the rabbit.

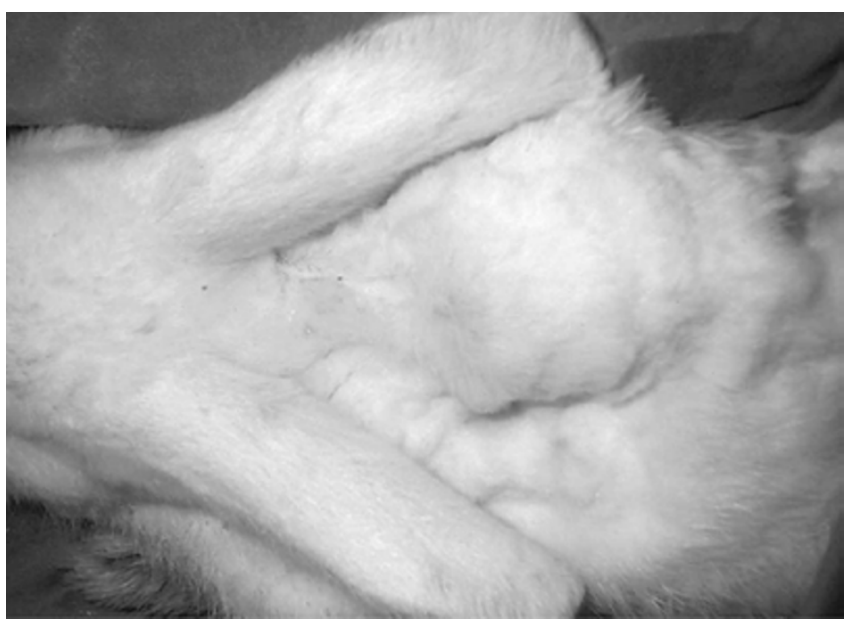

Figure 6

Inflated tissue expander.

expanders were created between the skin (panniculus carnosus was included) and the deep fascia by blunt dissection. $10 \mathrm{ml}$ isotonic saline was injected into the expanders intra-operatively. The second saline injection was performed in the post-operative fifth day and $10 \mathrm{ml}$ isotonic was given. Later, each expander was inflated at three days intervals with $10 \mathrm{ml}$ isotonic saline under aseptic conditions. The last expansion was done in the $16^{\text {th }}$ postoperative day, and all expanders were inflated with total $50 \mathrm{ml}$ saline. 


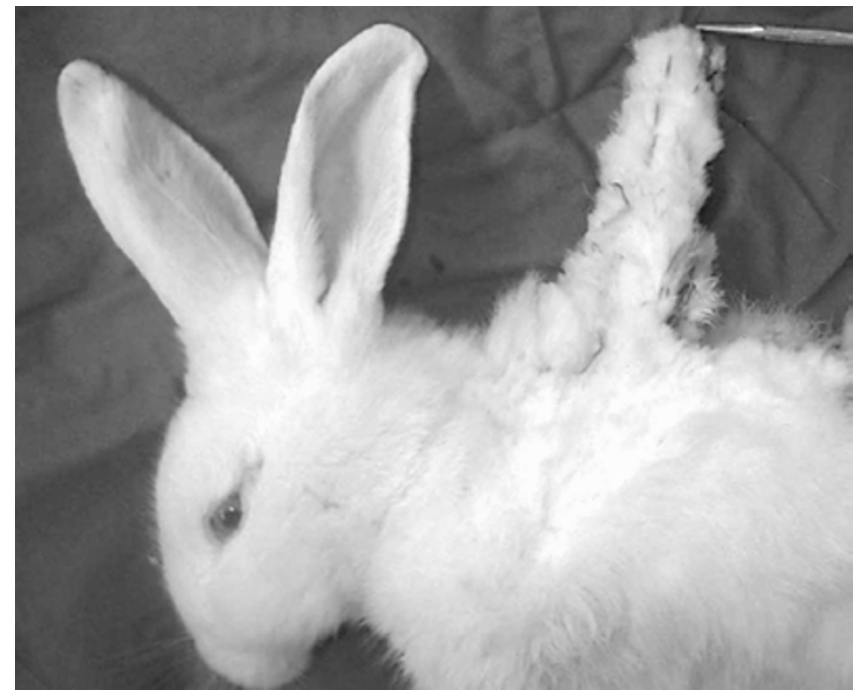

Figure 7

New ear which was reconstructed with tri-lobed flap.

\section{Application of alloplastic material}

Porous polyethylene (Medpor ${ }^{\circledR}$ ) implant in $80 \mathrm{~mm}$ length and $3 \mathrm{~mm}$ width was applied in one rabbit in the expanded group. Base of this implant was sutured to the deep fascia and located between the flaps. This rabbit was followed for one more month.

\section{Macroscopic evaluation}

Viable parts of the flaps were determined and percentages of viable flaps were estimated by a computer-assisted analysis of the images. Since the demarcation between viable and necrotic tissues was easily identified, it was not necessary to use vital dyes to assess flap necrosis. Views of the flaps were transferred to a computer with a digital camera and percentages of necrotic areas were calculated using a computer-assisted analysis (with Adobe Photoshop 6.0 software). The formula below was used: Viable flap area $\left(\mathrm{mm}^{2}\right) /$ Total flap area $\left(\mathrm{mm}^{2}\right) \times 100$

\section{Evaluation of perfusion}

Perfusion of the flaps was evaluated by nuclear medicine techniques. Static images were acquired by using a gamma camera (Siemens e.Cam Single, Illinois, USA) to observe the perfusion visually after injection of $0.5 \mathrm{mCi}$ Technetium-99m pertecnetate. For quantitative evaluation, 0.1 $\mathrm{mCi}$ of Technetium-99m pertecnetate was injected subcutaneously to the flap and dynamic imaging was performed by acquisition of 1 second frames for 10 minutes. Data were processed to obtain a decay corrected timeactivity curve of radiotracer washout. Benzylpenicillin $1 \mathrm{~g}$ was given intramuscularly for five days postoperatively.
Since the number of animals was small, statistical analysis could not be performed.

\section{Results}

No rabbit died of the procedures, and they were still alive 21 days after the procedures.

\section{Non-expanded group}

Flaps were created at the same time as in the expanded group. Subtotal flap necrosis was seen after the elevation of the flap. Two flaps had necrosis of more than $50 \%$ percent in post-operative $7^{\text {th }}$ day and the last two flaps also had necrosis of $50 \%$ of the flap in post-operative $21^{\text {st }}$ day. These flaps were not evaluated with Technetium-99m scintigraphy.

\section{Expanded group}

Minimal tip necrosis was seen in one rabbit around the suture line. All flaps were intact in post-operative $21^{\text {st }}$ day. Results confirmed the perfusion and viability of the flaps (Figures 8 and 9). Flaps were well perfused.

We used porous polyethylene (Medpor ${ }^{\circledR}$ ) implant in 80 $\mathrm{mm}$ length and $3 \mathrm{~mm}$ width in one rabbit in expanded group. Base of this implant was sutured to the deep fascia and located between the flaps. The rabbit was followed for one month and there was no complication. An erect flap was created with this alloplastic material (Figure 10).

Results of macroscopic evaluation were listed in Table 1.

\section{Discussion}

Tri-lobed skin flap is a relatively new flap. Although many local flaps were reported with success in reconstructive surgery there are few reports related with tri-lobed flap and no animal model was presented in the literature.

Iida presented two kinds of tri-lobed flap: type I flap, which could be moved mainly by rotation, and type II, which compared with type I could serve as an advanced flap or transposed flap. Both flaps consisted of three triangular flaps. Flaps described in our study were totally different from the flaps of Iida. Our flaps were elliptical and more simple and easy to perform. Furthermore, they can be considered as modification of bi-lobed flaps. Bi-lobed flaps are often used when the primary closure of a skin defect is difficult, but there have been few reports on its method of design [12]. Esser first described the bi-lobed flap in 1918 [13]. Esser's initial bilobed flap design depicted two transposition flaps in equal size transferred to cover distal nasal tip wounds. McGregor and Soutar theoretically demonstrated a method for designing the bilobed flap [14]. They roughly classified bi-lobed flaps into type I and type II flaps. One of the most detailed reports was presented by Cook [15]. Cook stated that, depending 


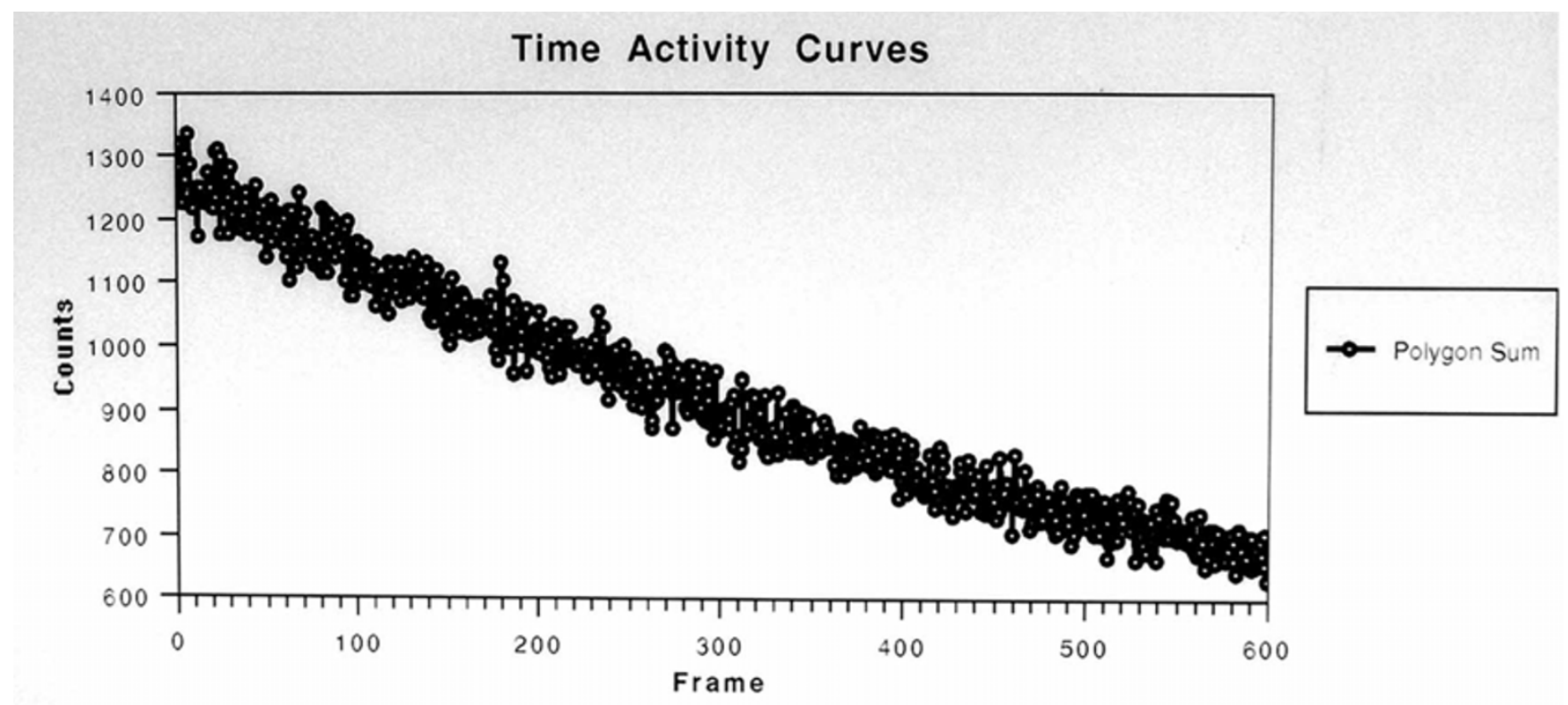

Figure 8

Evaluation of the flap with Technetium-99m scintigraphy: Static view of the flap.

on the flap's anatomic location, the surgeon had a great ability to vary the size of each lobe of this flap.

In this study we tried to perform an animal model with expanded tri-lobed skin flap. We were inspired by sizes of rabbit ears and aimed to obtain long but narrow flaps safely using an expander. As far as we know, there has not been an animal model for reconstruction of ears.

Reconstruction of the ear is still a challenge in plastic surgery since ear has a special and complex anatomy. The normal external ear forms an angel about 23 degrees with temporal area [4]. Diverse materials and methods have been used in auricular region. The earliest account of auricular reconstruction appears to have been written in about 600 B.C. by Sushruta and a slightly more professional procedure than that of Sushruta was recommended in about 300 A.D. by Celsus, who described the repair of an auricle by creating quadrangular advancement flaps and the treatment of concomitant atresia by drilling the bone and plunging the hole. As early as 1597, the Italian surgeon Tagliacozzi described and illustrated repair of both upper and lower ear deformities with skin flaps from behind the auricular region [5]. Until today, more flaps, techniques and implantation materials have been described for reconstruction of the ear [6-9]. Generally multiple surgical procedures were required in reconstruction of congenital microtia. The surgical reconstruction procedure for microtia was established with the advent of
Tanzer's operation [7]. Excellent tissue is required for covering the framework in all techniques. Since this tissue should have similar original texture, color and hair bearing characteristics of the original ear, local flaps gained more popularity $[10,11]$.

Neumann first applied the concept of tissue expansion to ear reconstruction and introduced the idea of expansion to the field of surgery [12]. One of the largest series was presented by Brent in 1992 [13]. Tanino and Miyasaka reported $14 \%$ exposure of the expander in microtia reconstruction as a complication [14]. Hata et al. also presented their experiences in ear reconstruction with tissue expander [3]. The Chiba University schedule for total ear reconstruction includes three stages [15]. Tissue expander is used in the first stage. The superior match of color and texture achieved with the tissue expander as compared with the results achieved with conventional methods of microtia repair is one of the most important merits of the expansion procedure [3]. Another important merit of the expansion procedure is the recovery and maintenance of skin sensation; however, because the expanded fascia and grafted skin cover the posterior surface of the auricle in graft, sensation in this region will completely disappear postoperatively.

The ear is a very complex organ and there is no animal which has ears similar to those of human beings. There are two major considerations for successful total-ear 


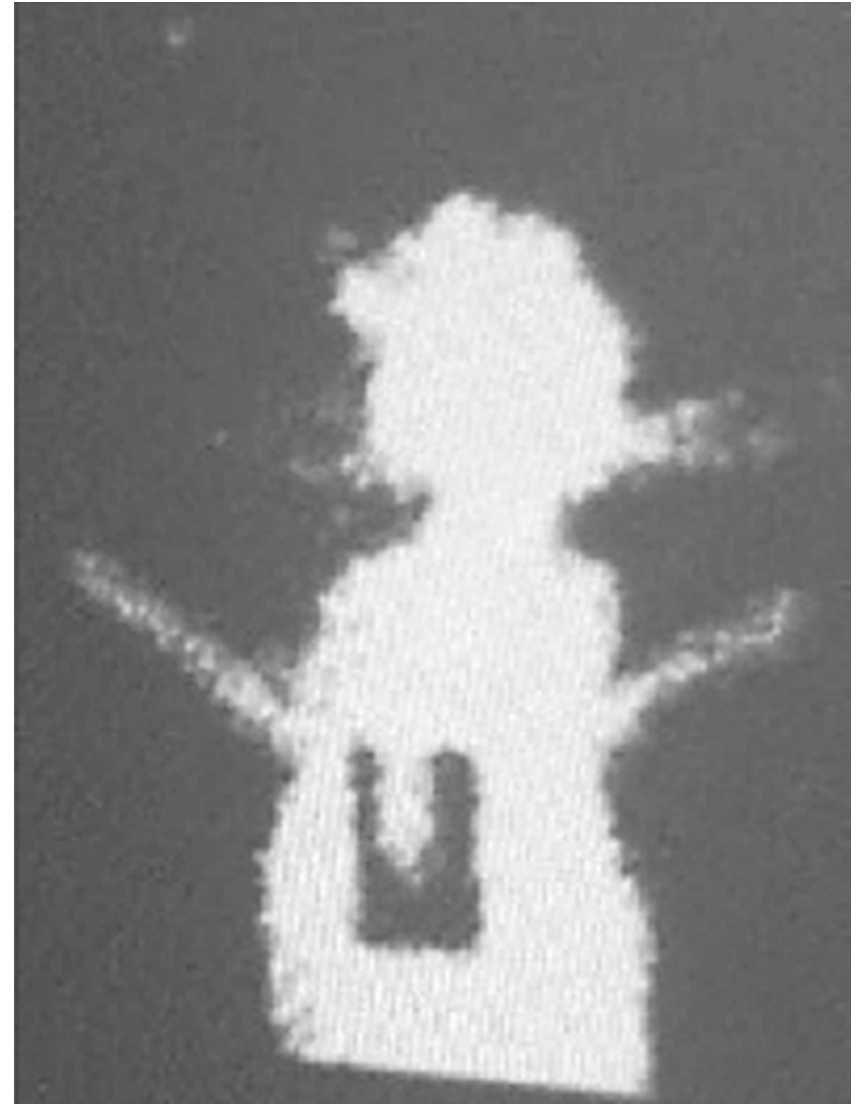

\section{Figure 9}

Evaluation of the flap with Technetium-99m scintigraphy: Dynamic view of the flap. Time-activity curve of radiotracer washout.

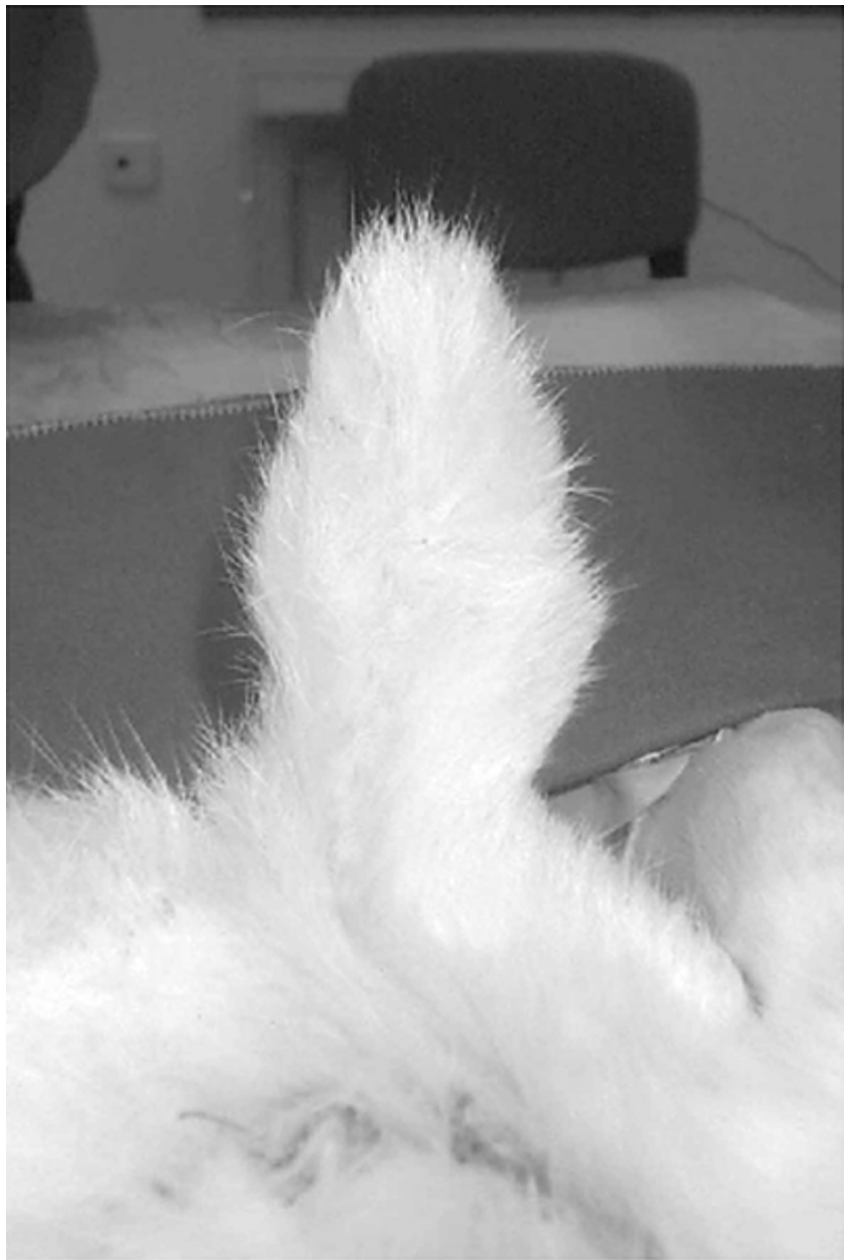

Figure 10

Erectly view of the tri-lobed flap with porous polyethylene implant.

Table I: Macroscopic evaluations of the flaps:

\begin{tabular}{|c|c|c|c|c|}
\hline Group & Rabbit No: & Post-operative day 7 th & Post-operative day I4 th & Post-operative day 2 Ist \\
\hline \multirow[t]{4}{*}{ Non-expanded group } & I & $72 \%$ & $60 \%$ & $41 \%(*)$ \\
\hline & 2 & $45 \%(*)$ & & \\
\hline & 3 & $40 \%(*)$ & & \\
\hline & 4 & $68 \%$ & $63 \%$ & $40 \%(*)$ \\
\hline \multirow[t]{4}{*}{ Expanded group } & 5 & $100 \%$ & $95 \%$ & $95 \%$ \\
\hline & 6 & $100 \%$ & $100 \%$ & $100 \%$ \\
\hline & 7 & $100 \%$ & $100 \%$ & $100 \%$ \\
\hline & 8 & $100 \%$ & $98 \%$ & $98 \%$ \\
\hline
\end{tabular}

Ratios of viable areas of the flaps in post-operative periods. $(*)$ indicates that this rabbit was excluded the study since the necrosed area of the flaps more than $50 \%$ and this flap was not evaluated with scintigraphy. 
(5) erect cylindrical tissue can be obtained,

(6) since the new ear is reconstructed with two lobes of the flap, edges of the ear could be created easily,

(7) design of the flap is not complex and does not require geometrical knowledge.

The aim of this study was to obtain a reliable flap and thus create an alternative for ear reconstruction. The most important part of ear reconstruction is creation of a framework to give a shape to the new ear. We also investigated whether the flap was resistant to alloplastic materials in one rabbit and obtained promising results.

\section{Conclusion}

It can be concluded that tri-lobed flaps can be obtained successfully although they cause some risks due to their sizes. Since tri-lobed flap can achieve an epithelized tissue in two sides of an organ as in the ears, they can be alternative in partial or total ear reconstruction.

Any process without a framework can not be a model for ear reconstruction. Although we had only one rabbit with aloplastic material in expanded group, we speculated that this flap may be used with autogenous and alloplastic materials.

A new ear which is erect, sufficiently angled and thin and thus easily adapted to the shape of the framework, and resistant to external traumas could be reconstructed with this flap without any donor site problems. Finally, this flap is not only suitable for ear reconstruction but also it may be used in reconstruction of cylindrical organs such as penis or finger.

\section{Competing interests}

None declared.

\section{Authors' contributions}

E. Copcu designed the study, performed the operations and prepared the manuscript. M. Yazici and B. Etensel participated in the performing of the operations. Y. Yurekli performed the scintigraphy. M. Balkaya participated in the design of study and performed the statistical analysis. All authors read and approved the final manuscript.

\section{References}

I. Harashina T, Maruyama Y, Kitamura K: The trilobed flap. Case report. Plast Reconstr Surg 1977, 60:623-624.

2. Weerda $\mathrm{H}$ : [A trilobed rotation cheek flap for closure of facial defects (author's transl)]. HNO 1979, 27:358-359.

3. Ohtsuka $H$, Miki $Y$, Shioya $N$ : Trilobed flap in facial reconstruction. Br J Plast Surg 1982, 35:493-497.

4. Tanabe HY, Tai Y, Kiyokawa K, Yamauchi T: Nipple-areola reconstruction with a dermal-fat flap and rolled auricular cartilage. Plast Reconstr Surg 1997, 100:431-438.
5. Pompei S, Tedesco M: A new surgical technique for the correction of the inverted nipple. Plast Reconstr Surg 1999, 23:37I-374.

6. Ao M, Mae O, Namba Y, Asagoe K: Perforator-based flap for coverage of lumbosacral defects. Plast Reconstr Surg 1998, 101:987-991.

7. Copcu E: Postauricular trilobed skin flap for reconstruction of postauricular sulcus. Eur J Plast Surg 2002, 25:34I-343.

8. Park C, Suk Roh T: Total ear reconstruction in the devascularized temporoparietal region: I. Use of the contralateral temporoparietal fascial free flap. Plast Reconstr Surg 200I, 108: II45-II53.

9. Radovan C: Tissue expansion in soft-tissue reconstruction. Plast Reconstr Surg 1984, 74:482-492.

10. Hata Y, Hosokawa K, Yano K, Matsuka K, Ito O: Correction of congenital microtia using the tissue expander. Plast Reconst Surg 1989, 84:74I-75I.

II. lida N, Ohsumi N, Sakai M: A trilobed flap for reconstruction of nasal skin defects. Plast Reconstr Surg 1997, 100:991-995.

12. lida N, Ohsumi N, Tonegawa M, Tsutsumi K: Simple method of designing a bilobed flap. Plast Reconstr Surg 1999, 104:495-499.

13. Esser JFS: Gestielite lokale Nasenplastik mit zweizipfligem Lappen, Deckung des sekundaren Defktes vom ersten Zipfel durch den zweiten. Dtsch Z Chir 1918, I43:385-90.

14. McGregor JC, Soutar DS: A critical assessment of the bilobed flap. BrJ Plast Surg 198I, 34:197-205.

15. Cook JL: A review of the bilobed flap's design with particular emphasis on the minimization of alar displacement. Dermatol Surg 2000, 26:354-62.

16. Farkas LG: Anthropometry of the Head and Face. New York: Raven 1984.

17. Aguilar EF 3rd: Auricular reconstruction of congenital microtia (grade III). Laryngoscope 1996, I06: I-26.

18. Nagata S: Reconstruction of the auricle. Plast Reconstr Surg 1994, 93:225-231.

19. Tanzer RC: Total reconstruction of the auricle. The evolution of a plan of treatment. Plast Reconstr Surg 197I, 47:523-533.

20. Brent B: Earlobe construction with an auriculomastoid flap. Plast Reconstr Surg 1976, 57:389-391.

21. Brent $B:$ Technical advances in ear reconstruction with autogenous rib cartilage grafts - personal experience with I,200 cases. Plast Reconstr Surg 1999, 104:319-334.

22. Masson JK: A simple island flap for reconstruction of conchahelix defects. Br J Plast Surg 1972, 25:399-403.

23. Renard A: Postauricular flap based on a dermal pedicle fýr ear reconstruction. Plast Reconstr Surg |98|, 68:159-165.

24. Neumann CG: The expansion of an area of skin by progressive distension of a subcutaneous balloon. Plast Reconstr Surg 1957, 19:124-127.

25. Brent $B$ : Auricular repair with autogenous rib cartilage grafts: Two decades of experience with 600 cases. Plast Reconstr Surg 1992, 90:355-374.

26. Tanino R, Miyasaka M: Reconstruction of microtia using tissue expander. Clin Plast Surg 1990, 17:339-353.

27. Danino AM, Yoshimoto S, Ichinose M, Kuroki T: The Chiba University chronology for total ear reconstruction. Plast Reconstr Surg 2000, 106:218-219.

\section{Pre-publication history}

The pre-publication history for this paper can be accessed here:

http://www.biomedcentral.com/1471-2482/3/13/prepub 